\title{
Identificação de proteases produzidas pelo fungo entomopatogênico Beauveria bassiana (Bals) Vuill. Cepa CG432 previamente ativada em insetos vivos de broca do café ((Hypothenemus hampei $))^{1}$
}

\section{Identification of proteases produced by entomopathogenic fungi Beauveria bassiana (Bals) Vuill. strain CG432 previously activated in coffee berry borer alive (Hypothenemus hampei)}

\author{
Geni Silva Varéa ${ }^{2 *}$ J Jakeliny Akemi Yamamoto Oliveira ${ }^{3}$; \\ Vanessa Hitomi Sugahara ${ }^{3}$; Eliana Tiemi Ito ${ }^{3}$; Jurandir Pereira Pinto ${ }^{4}$; \\ Dalva Trevisan ${ }^{5}$; Humberto Josué de Oliveira Ramos ${ }^{6}$; \\ Diogo Maciel de Magalhães ${ }^{7}$; Luiz Filipe Protásio Pereira ${ }^{8}$
}

\begin{abstract}
Resumo
Conídios de fungos entomopatogênicos atravessam o exoesqueleto do inseto pela ação mecânica do tubo germinativo e produção de múltiplas isoformas de proteases, quitinases e lipases em resposta à composição da cutícula do inseto. Desta forma o objetivo deste trabalho foi extrair, purificar e caracterizar a estrutura de proteases produzidas em cultivo submerso por Beauveria bassiana CG432 previamente ativada em adultos vivos de broca-do-café (Hypothenemus hampei). Uma suspensão contendo $10^{6}$ conídios ativados $/ \mathrm{mL}$ foi inoculada em meio de cultura líquido a $28^{\circ} \mathrm{C}, 150 \mathrm{rpm}$ por 3 dias. $\mathrm{O}$ extrato de proteases (EP) foi obtido da centrifugação a $8000 \mathrm{~g}$ por 20 minutos, fracionado e concentrado por ultrafiltração em membrana de porosidade controlada $100 \mathrm{kDa}$ e $3 \mathrm{kDa}$, respectivamente. A cromatografia de gel filtração em Sephadex G-100 separou um pico proteico (Pico II) que apresentou $56 \%$ de resíduos do aminoácido ácido aspártico quando analisado por HPLC em coluna de fase reversa ODS-C18; atividade específica 43 vezes superior ao EP sobre soro albumina bovina; atividade de protease tipo-subtilisina e uma única banda proteica revelada por nitrato de prata e Coomassie Brilhant Blue em zimograma sobre gelatina por eletroforese PAGE em condições nativas. A homogeneidade do Pico II foi confirmada pela revelação de uma única banda durante a determinação do $\mathrm{pH}$ isoelétrico igual a 4,5, porém a determinação da massa molecular separou 2 bandas de 23 e $26 \mathrm{kDa}$ por eletroforese PAGE-2D. As proteases foram caracterizadas como serino proteases com resíduo cisteína importante para a atividade, pois foram inibidas por fluoreto fenil-metil-sufonil e ácido $p$-cloromercúriobenzóico. As proteases do Pico II apresentaram Km 4x10-4 sobre substrato tipo-subtilisina.

Palavras-chave: Beauveria bassiana, proteases, purificação, caracterização estrutural
\end{abstract}

\footnotetext{
${ }^{1}$ Parte de dissertação e Mestrado em Biotecnologia, Universidade Estadual de Londrina.

${ }^{2}$ Prof $^{a}$. do Dept ${ }^{\circ}$. Bioquímica e Biotecnologia. Universidade Estadual de Londrina, UEL, Londrina, PR. E-mail: genivarea@uel.br

${ }^{3}$ Discente(s) de Mestrado Biotecnologia da UEL, Londrina, PR. E-mail: jakeahemy@yahoo.com.br; vanessa_hitomi@yahoo. com.br; elianaito@hotmail.com

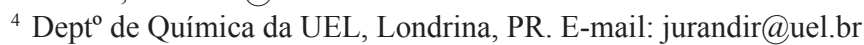

${ }^{5}$ Prof $^{a}$ do Dept ${ }^{\circ}$ de Química da da UEL, Londrina, PR. E-mail: dalva@uel.br

${ }^{6}$ Prof. da Universidade Federal de Viçosa, UFV, Viçosa, MG. E-mail:humramos.ufv.br@gmail.com

${ }^{7}$ Bolsista DTI Instituto Agronômico do Paraná, Londrina, PR. E-mail: diogolbi@gmail.com

${ }^{8}$ Pesquisador Embrapa Café. E-mail: filipe.pereira@embrapa.br

* Autor para correspondência
} 


\begin{abstract}
Conidia of entomopathogenic fungi can penetrate the insect exoskeleton both by mechanic action of the germinative tube and by production of multiple proteases, chitinases, and lipases in response to the composition of the insect cuticle. Therefore the purpose of this work was to produce, to purify, and to characterize the structure of the proteases produced by the fungus Beauveria bassiana CG432, previously activated in adults of coffee berry borer (Hypothenemus hampei) grown under submerged culture conditions. A suspension containing $10^{6}$ activated conidia $/ \mathrm{mL}$ was inoculated to a culture medium at $28^{\circ} \mathrm{C}$ and $150 \mathrm{rpm}$ for 3 days. Protease extracts, were obtained by centrifugation at $8000 \mathrm{~g}$ for 20 minutes, were fractionated and were concentrated by ultrafiltration using controlled porosity membranes of 100 $\mathrm{kDa}$ and $3 \mathrm{kDa}$, respectively. Gel filtration chromatography on Sephadex G-100 isolated one protein peak (peak II), which contained $56 \%$ of residues of the aminoacid aspartic acid, characterized by HPLC using an ODS-C18 reverse phase column. The peak protein showed specific activity 43 times superior when compared to the free-cell extract in bovine serum albumin, subtilisin-like protease activity, and a single protein band reveled by Brilliant Coomassie Blue on a gelatin zimogram PAGE electrophoresis, by native conditions. The homogeneity of peak II was confirmed by revelation of a single band during determination of the isoelectric $\mathrm{pH} 4.5$, but molecular mass determination by PAGE-2D electrophoresis showed 2 bands of 23 and $26 \mathrm{kDa}$. Proteases were characterized as serine proteases with cysteine residues important to activity, since they had been inhibited by phenylmethylsulphonyl fluoride and $p$-chlormercuricbenzoic acid. Peak II proteases showed Km of $4 \times 10^{-4}$ on subtilisin-like substrate.
\end{abstract}

Key words: Beauveria bassiana, proteases, purification, structural characterization

\section{Introdução}

Fungos entomopatogênicos causam doença e morte natural de insetos e por isto são considerados como importantes agentes de proteção das plantas contra insetos-praga e apresentam grande potencial de utilização no controle biológico de interesse comercial (ALVES, 1998). A infecção ocorre por via tegumentar através da ação conjunta da força mecânica exercida pelo crescimento do tubo germinativo e a produção de enzimas hidrolíticas que degradam os polímeros estruturais da cutícula, a qual é revestida por lipídeos e formada por um arcabouço constituído por 55 a $80 \%$ de proteínas (HEPBURN, 1985; NEVILLE, 1975) de natureza hidrofílica na cutícula mole, mais interna e hidrofóbica na cutícula dura mais externa. Estas proteínas envolvem microfibrilas de quitina de 2,5 a 3,0 mm de diâmetro, que perfazem de $20-50 \%$ do peso seco da cutícula (CHAPMAN, 1998).

Proteases produzidas pelo fungo entomopatogênico Beauveria bassiana foram citadas inicialmente como toxinas produzidas em cultivo submerso com dose letal $\left(\mathrm{DL}_{50}\right)$ de 26,1 mg de proteínas por inseto tratado (KUCERA;
SAMSINAKOVA, 1968). A seguir a ação de proteases, quitinases e lipases têm sido relacionadas com a degradação da cutícula de insetos a partir do cultivo de B. bassiana (GUPTA et al., 1992) e Metarhizium anisopliae (St LEGER; CHARNLEY; COOPER, 1986a), outro deuteromiceto entomopatogênico extensivamente estudado e adotado como sistema modelo comparativo de outros fungos entomopatogênicos. Bidochka e Khachatourians (1990) demonstraram que cepas mutantes deficientes para a produção de proteases apresentaram redução da virulência sobre larvas migratórias (Melanoplus sangunípes).

A influência da natureza de diferentes substratos, adição de cutícula de insetos e outros nutrientes sobre a produção de enzimas degradadoras de cutícula tem elucidado os mecanismos de hidrólise ( $\mathrm{St}$ LEGER; COOPER; CHARNLEY, 1986b), adsorção (BIDOCHKA; KHACHATOURIANS, 1994) e regulação de proteases extracelulares responsáveis pela virulência dos fungos entomopatogênicos. Múltiplas isoformas de proteases produzidos por $M$. anisopliae com pH ótimo alcalino de 8 a 9,5 e pI entre 9 e 10 tipo-subtilisina $(\operatorname{Pr} 1)$ e tipo- 
tripsina (Pr2) foram caracterizadas como serinoproteases (St LEGER; CHARNLEY; COOPER, 1987a), metaloproteases (St LEGER, BIDOCHKA; ROBERTS, 1994) e cisteíno-proteases (COLE; CHARNLEY; COOPER, 1993).

Diferentes cepas de $B$. bassiana também produziram proteases tipo-subtilisina, $\operatorname{Pr} 1 \mathrm{Bb}$ (JOSHI; St LEGER; BIDOCHKA, 1995) e tipotripsina, BBP (URTZ; RICE, 2000), e as Proteases I e II produzidas em meio de cultura enriquecidos com larvas moídas de Apis mellífera e plasma sanguíneo, respectivamente (CHRZANOWSKA; BANAS; KOLACZKOWSKA, 2001).

A atividade lipolítica e proteolítica foi relacionada com a patogenicidade de $B$. bassiana e $M$. anisopliae sobre insetos de broca-do-café (Hypothenemus hampei) (GIRALDO-CARDOZO et al., 2001).

A cepa brasileira de B. bassiana CG432, selecionada como maior produtora de conídios e causadora de mortalidade de broca-do-café (NEVES; HIROSE, 2005) produziu proteases extracelulares em menor tempo de cultivos submersos, quando previamente ativadas em insetos vivos de broca-docafé (ITO et al., 2007).

Considerando que a multiplicidade das enzimas degradadoras de cutícula é influenciada pela natureza dos substratos disponíveis para o crescimento e virulência dos fungos entomopatogênicos, avaliouse o fungo $B$. bassiana como agente de controle biológico para a broca-do-café (Hypothenemus hampei) um dos insetos-praga das lavouras de café. O objetivo deste trabalho foi extrair, purificar e analisar parâmetros estruturais e cinéticos de proteases produzidas pela cepa brasileira de $B$. bassiana CG432 previamente ativada em insetos vivos de broca-do-café na tentativa de elucidar o preciso papel das proteases relacionada a especificidade no processo de infecção do inseto.

\section{Material e Métodos}

Microorganismo e ativação do inóculo

A cepa de $B$. bassiana CG432 procedente da EMBRAPA/Cenargen e armazenada no Banco de Entomopatógenos do Departamento de Agronomia da Universidade Estadual de Londrina foi isolada da família Membracidae (Homoptera), na cidade de Natal, Estado do Rio Grande do Norte, região Nordeste do Brasil. A ativação em insetos vivos de broca-do-café e o isolamento dos conídios ativados foram realizados conforme descrito por Ito et al. (2007).

Condições de cultivo e obtenção do extrato de proteases

Cultivos submersos foram inoculados com $10^{6}$ conídios recém-ativados $/ \mathrm{mL}$ e conduzidos a $28^{\circ} \mathrm{C}, 150 \mathrm{rpm}$ em frascos erlenmeyer de 1000 $\mathrm{mL}$ contendo $250 \mathrm{~mL}$ de meio líquido constituído por $1 \%$ glucose, $0,5 \%$ extrato de levedura, $0,16 \%$ $\mathrm{NaNO}_{3}, 0,11 \% \mathrm{Na}_{2} \mathrm{HPO}_{4} \cdot 7 \mathrm{H}_{2} \mathrm{O}, 0,1 \% \mathrm{KCl}, 0,06 \%$ $\mathrm{MgSO}_{4} \cdot 7 \mathrm{H}_{2} \mathrm{O}, 0,04 \% \mathrm{KH}_{2} \mathrm{PO}_{4}$ (ALVES, 1998). Os cultivos foram interrompidos no terceiro dia através da filtração á vácuo em banho de gelo e centrifugação a $8000 \mathrm{~g}$ por 20 minutos. Os sobrenadantes reunidos formaram o extrato de proteases (EP).

\section{Purificação das proteases}

As proteínas do extrato de proteases (EP) foram concentradas por ultrafiltração em equipamento Stirred Cell (Amicon) utilizando membranas de porosidade controlada de $100 \mathrm{kDa}$ (PBHK polietersulfona Millipore) e $3 \mathrm{kDa}$ (YM3 celulose regenerada Millipore), respectivamente. $\mathrm{O}$ concentrado $\mathrm{C}_{3 \mathrm{kDa}}$ contendo $8 \mathrm{mg}$ de proteínas foi diafiltrado por três vezes no mesmo equipamento com $250 \mathrm{~mL}$ de tampão fosfato $5 \mathrm{mM}$, pH $7 \mathrm{e}$ fracionado por cromatografia de exclusão molecular 
em gel Sephadex G-100 em coluna de vidro $(2 \mathrm{x}$ $104 \mathrm{~cm}$ ) utilizando como eluente o mesmo tampão da diafiltração e fluxo $18 \mathrm{~mL} / \mathrm{h}$. As frações de $3 \mathrm{~mL}$, coletadas a cada 10 minutos, foram monitoradas quanto à presença de proteínas por leitura de absorvância em comprimento de onda $280 \mathrm{~nm}$. As frações protéicas constituintes do pico II com atividade de proteases foram reunidas e após o volume foi reduzido até $10 \mathrm{~mL}$ por liofilização e diálise exaustiva contra água deionizada em membrana de $12 \mathrm{kDa}$, foram quantificadas quanto ao teor de proteínas pelo método de Bradford (1976) e atividade de proteases sobre soro albumina bovina e substratos específicos de proteases tipo-subtilisina e tipo-tripsina.

\section{Determinação de atividade de proteases}

Alíquotas de $500 \mu \mathrm{L}$ do EP contendo $100 \mu \mathrm{g}$ de proteínas e das frações obtidas da purificação foram incubadas a $37^{\circ} \mathrm{C}$ por 1 hora com $250 \mu \mathrm{L}$ do tampão glicina-NaOH $5 \mathrm{mM}$ pH 9,5 e $250 \mu \mathrm{L}$ de soro albumina bovina $5 \mathrm{mg} / \mathrm{mL}$. A reação foi interrompida com $250 \mu \mathrm{L}$ de ácido tricloroácetico $10 \%$ e centrifugada a $3000 \mathrm{~g}$ por 15 minutos. A concentração de peptídeos solúveis do sobrenadante foi determinada pelo método de Hartree (1972) utilizando equação de regressão $(\mathrm{y}=0,00192 \mathrm{x}+$ $0,079 \mathrm{R}^{2}=0,998$ ) obtida da curva de calibração construída com soro albumina bovina e absorvância de $650 \mathrm{~nm}$. Uma unidade de atividade proteases (UP) foi definida como a quantidade de enzima que libera $1 \mu \mathrm{g}$ de peptídeos solúveis por $\mathrm{mL}$ do EP nas condições da reação.

\section{Especificidade das proteases}

Alíquotas de $50 \mu \mathrm{L}$ do Pico II obtido da cromatografia em gel filtração contendo $10 \mu \mathrm{g}$ de proteínas foram incubadas com $400 \mu \mathrm{L}$ de tampão Tris- $\mathrm{HCl} 15 \mathrm{mM}$ pH 8,5 e $50 \mu \mathrm{L}$ dos substrato específicos de proteases tipo- subtilisina e tipotripsina Suc-Ala-Ala-Pro-Phe- $p$-nitroanilida e N-Benzoil-Phe-Val-Arg- $p$-nitroanilida $1 \mathrm{mM}$, respectivamente a $28^{\circ} \mathrm{C}$ por 30 minutos (TIAGO et al., 2004). A reação foi interrompida pela adição de $250 \mu \mathrm{L}$ de ácido acético $30 \%$ e centrifugada a 1250 $g$ por 5 minutos. A concentração do cromogênico $p$-nitroanilina do sobrenadante foi determinada por leitura de absorvância em $410 \mathrm{~nm}$ e equação de regressão ( $\left.\mathrm{y}=0,0394+0,003 ; \mathrm{R}^{2}=0,9996\right)$ obtida da curva de calibração construída com 0,1 a $5 \mu \mathrm{g} / \mathrm{L}$ de $p$-nitroanilina. Uma unidade de atividade de protease tipo subtilisina e tipo-tripsina foi definida como a quantidade de enzima que libera $1 \mu \mathrm{g}$ de $p$-nitroanilina por $\mathrm{mL}$ do Pico II nas condições da reação.

\section{Atividade inibidora das proteases}

As soluções de inibidores serino-proteases (Fluoreto Fenil-Metil-Sulfonil), metalo proteases (Ácido Etileno Diamino Tetracético), cisteínoproteases $\left(\mathrm{HgCl}_{2}\right.$, AIA, $p$-hidroximercuriobenzeno e ácido p-cloromercurobenzóico) e aspartato proteases (Ácido Indol Acético) em concentração final de 10 $\mathrm{mM}$ na reação, foram pré-incubadas com alíquotas de $50 \mu \mathrm{L}$ do Pico II e $350 \mu \mathrm{L}$ de Tris-HCl 0,1 M (pH $8,5)$ antes da adição de ambos substratos específicos de proteases tipo-subtilisina ou tipo-tripsina. Após foram adicionados os substratos específicos de proteases tipo-subtilisina ou tipo-tripsina 1 $\mathrm{mM}$, respectivamente. A reação foi interrompida pela adição de $250 \mu \mathrm{L}$ de ácido acético $30 \%$ e centrifugada a $1250 \mathrm{~g}$ por 5 minutos. A concentração do cromogênico $p$-nitroanilina do sobrenadante foi determinada por leitura de absorvância em 410 $n m$ e equação de regressão $\left(y=0,0394+0,003 ; R^{2}\right.$ $=0,9996$ ) obtida da curva de calibração construída com 0,1 a $5 \mu \mathrm{g} / \mathrm{L}$ de $p$-nitroanilina. Uma unidade de atividade de protease tipo-subtilisina e tipo-tripsina foi definida como $\mu \mathrm{g}$ de p-nitroanilina liberada por $\mathrm{mL}$ do Pico II nas condições da reação. 


\section{Cinética das proteases}

O valor de $\mathrm{Km}$ das proteases do Pico II foi determinado nas mesmas condições descritas no ítem 5 utilizando concentrações de 0,25 a 1,5 $\mathrm{mM}$ do substrato de proteases tipo-subtilisina e determinado pelo gráfico de Lineweaver-Burke.

Caracterização de proteínas por eletroforese em gel PAGE nativa

Alíquotas de $50 \mu \mathrm{L}$ do Pico II obtidos pela cromatografia de exclusão molecular contendo 10 $\mu \mathrm{g}$ de proteínas foram analisadas por eletroforese descontínua em gel de poliacrilamida (PAGE) a $10 \%$ em condições nativas em tampão TRIS$\mathrm{HCl}$ 3,78 M pH 8,9 a $100 \mathrm{mV}$ (DAVIS, 1964). As bandas protéicas foram reveladas pela complexação com nitrato de prata (NIELSEN; BROWN, 1984). Zimogramas em gel PAGE nas mesmas condições adicionados de $0,02 \%$ de gelatina (Difco) foram reveladas por coloração com Coomassie Brilhant Blue R-250.

Análise da composição de aminoácidos da protease

A composição de aminoácidos da protease foi quantificada pela metodologia do Yang et al. (2002). Alíquotas de $100 \mu \mathrm{L}$ do Pico II obtido da cromatografia de exclusão molecular contendo 20 $\mu \mathrm{g}$ de proteínas foi hidrolisada por ácido clorídrico $6 \mathrm{M}$ e aquecimento em mufla a $120^{\circ} \mathrm{C}$ por 24 horas em ampola de vidro, duplamente lacrada e analisada quanto à composição de aminoácidos por meio de cromatografia líquida de alta eficiência-CLAE (Shimadzu modelo CR10), utilizando coluna de fase reversa ODS-C18 (250 x 4,6 mm) acoplada a pré-coluna idêntica. A eluição foi realizada em fase móvel constituída por solução acetato de sódio 25 $\mathrm{mM}$ e metanol (38:62) cujo $\mathrm{pH}$ foi ajustado para 6,8 com ácido acético 5\%, a temperatura ambiente, utilizando detector de fluorescência operando em $420 \mathrm{~nm}$ para a excitação e $483 \mathrm{~nm}$ para emissão (Shimadzu modelo RF135).
Os tempos de retenção obtidos pela análise da amostra foram comparados com os tempos de retenção de soluções-padrão dos aminoácidos submetidos à derivatização com o 2,3-dicarboxaldeídonaftaleno (NDA) e cianeto de potássio (KCN). A derivatização dos padrões e da amostra foi realizada por aquecimento a $65^{\circ} \mathrm{C}$ por 25 minutos em microtubos para centrífuga (Eppendorf) utilizando $20 \mu \mathrm{L}$ das soluções de cada aminoácido isoladamente a $0,4 \mathrm{mg} / \mathrm{mL}$ e em mistura de $50 \mathrm{mg} / \mathrm{mL}$, utilizando $\mathrm{HCl} 0,1 \mathrm{M}, 40 \mu \mathrm{L}$ de tampão borato $50 \mathrm{mM}(\mathrm{pH} 8,5), 20 \mu \mathrm{L}$ de $\mathrm{KCN}$ $5 \mathrm{mM}$ e $20 \mu \mathrm{L}$ de NDA. A concentração $(\mu \mathrm{g} / \mathrm{mL})$ de aminoácidos da amostra foi determinada através de curvas de calibração correspondente a cada solução de aminoácido padrão e expressa em $\mu \mathrm{g} / \mathrm{mL}$.

\section{Caracterização por eletroforese PAGE 2D}

Alíquotas de $100 \mu \mathrm{L}$ do Pico II com atividade de proteases, contendo $20 \mu \mathrm{g}$ de proteínas, foram submetidas à isoeletrofocalização e PAGE2D segundo Dunn e Gorg (2001). Utilizouse tira de $13 \mathrm{~cm}$ de gel de poliacrilamida com gradiente de $\mathrm{pH}$ imobilizado 3-10 e foi submetida à isoeletrofocalização em aparelho IPGphor por 4 horas utilizando voltagens crescentes de 500, 1000, 12500 e 14000 a cada hora. Após a isoeletrofocalização, a tira de gradiente de $\mathrm{pH}$ imobilizado foi imersa em $20 \mathrm{~mL}$ de solução de tampão de equilíbrio Tris- $\mathrm{HCl} 50 \mathrm{mmol} / \mathrm{L} \mathrm{pH} \mathrm{8,8,}$ contendo uréia $6 \mathrm{~mol} / \mathrm{L}$, glicerol 30\% (p/v), SDS $2 \%(\mathrm{p} / \mathrm{v})$, solução de azul de bromofenol 0,25\% (p/v) e $50 \mathrm{mg}$ de ditiotreitol, por 15 minutos. Em seguida foram colocadas no mesmo tampão de equilíbrio, adicionados de $200 \mathrm{mg}$ de iodoacetamida por mais 15 minutos. Logo após foram lavadas em tampão de corrida e colocada em adesão na parte superior do gel. A segunda dimensão SDS-PAGE a 12,5\% (Cuba "Protean II" Bio-Rad) foi conduzida a $12^{\circ} \mathrm{C}$ a $15 \mathrm{~mA} /$ gel e $30 \mathrm{~mA} /$ gel sequencialmente (LAEMMLI, 1970).

Os géis bi-dimensionais (2-D) obtidos foram 
fixados em solução aquosa contendo $40 \%$ de etanol (v/v) e 10\% de ácido acético (v/v) por uma hora. Logo após a fixação, os géis foram corados em solução Coomassie Blue G-250 (CANDIANO et al., 2004) por pelo menos 12 horas e depois descorados com 2-3 lavagens de uma hora cada em água destilada. A imagem dos spots protéicos reveladas nos géis 2D foram digitalizadas com auxilio do scanner UMAX ImageScanner e do software de digitalização LabScan. As imagens obtidas foram analisadas pelo programa ImageMaster Platinum 6.0.

\section{Espectrofotometria de massa MALDI-TOF-TOF}

Inicialmente os spots foram excisados diretamente dos géis 2D com auxílio de ponteira de $1000 \mu \mathrm{L}$ cortada na ponta e transferidos para tubos de micro centrifuga. Para remoção do corante, os spots foram tratados com $50 \mu \mathrm{L}$ de solução 75 $\mathrm{mmol} / \mathrm{L}$ de bicarbonato de amônio em etanol $40 \%$. Os tubos foram agitados em vortex e deixados em repouso por 10 minutos antes de se retirar a fase sobrenadante e esta etapa foram realizadas de 5-8 vezes ou até que se observasse total descoloração dos spots.

Os spots descorados foram desidratados por 3 lavagens com $25 \mu \mathrm{L}$ de acetonitrila 100\%, secados a vácuo e tratados com solução tampão de bicarbonato de amônio $50 \mathrm{mM}$ em pH 8,0 contendo tripsina $20 \mu \mathrm{g} / \mu \mathrm{L}$ para digestão das proteínas dos spots. Os tubos foram deixados em gelo por uma hora e depois transferidos para estufa $37{ }^{\circ} \mathrm{C}$ por 16 horas. A solução foi transferida para eppendorf e a extração dos peptídeos restantes do spot foi feita pela adição de $20 \mu \mathrm{L}$ de solução contendo acetonitrila (ACN) 5\% e acido trifluoracetico (TFA) $1 \%$. Os tubos foram agitados, deixados em repouso por 10 minutos em temperatura ambiente e realizouse a coleta do sobrenadante. Esta etapa foi repetida 3 vezes e as soluções peptídicas coletadas foram acrescentadas àquela transferida inicialmente para eppendorf. A redução do volume e concentração da amostra foi realizada em equipamento speed-vac.
Um volume de $0,3 \mu \mathrm{L}$ de amostra foi cocristalizada com $0,3 \mu \mathrm{L}$ de matriz $(5 \mathrm{mg} / \mathrm{mL}$ de ácido $\alpha$-ciano-4-hidroxicinâmico solubilizado em solução TFA 1\% e ACN 5\%) diretamente na placa de MALDI a ser analisada no espectrômetro. A placa foi inserida na gaveta do equipamento e operada a partir do programa Flex Control. Foram obtidos primeiramente os espectros de massa (MS) e posteriormente os peptídeos selecionados foram fragmentados para obtenção dos espectros MS/ MS. A partir dos espectros de massa MS e MS/MS, analisados com o programa Flex Analysis 3.0, foram realizadas buscas nos bancos de dados do NCBI e Swiss-prot pelas seqüências peptídicas similares visando determinar a identidade das proteínas das amostras por PMF (Peptide mass fingerprinting) e MS/MS ion search, respectivamente. As pesquisas foram realizadas na web pelo site do Mascot (http:// www.matrixscience.com/search__ form_select. html).

\section{Resultados e Discussão}

\section{Purificação das proteases}

A cromatografia de gel filtração do concentrado $\mathrm{C}_{3 \mathrm{kDa}}$ (obtida da ultrafiltração) em Sephadex G-100 separou três frações protéicas (I,II e III), sendo que o Pico II (Figura 1), apresentou atividade de proteases sobre soro albumina bovina, apresentando fator de purificação 43 vezes superior ao EP inicial (Tabela 1). Considerando que as proteases de $B$. bassiana anteriormente caracterizadas, apresentaram massas moleculares em torno de 30 $\mathrm{kDa}$, a ultrafiltração removeu proteínas maiores que $100 \mathrm{kDa}$ (descartadas) e concentrou proteínas com massas moleculares entre 3 e $100 \mathrm{kDa}$, incluindo as proteases de interesse na membrana 3 $\mathrm{kDa}\left(\mathrm{C}_{3 \mathrm{kDa}}\right)$, com boa margem de segurança. Além disso, a diafiltração do concentrado $\mathrm{C}_{3 \mathrm{kDa}}$, realizada no mesmo equipamento, removeu metabólitos de baixa massa molecular como uma alternativa á diálise geralmente realizada por períodos de tempo prolongados. A eficiência da ultrafiltração 
foi confirmada porque a coluna de gel Sephadex G-100, separou além do pico II apenas um pico de proteínas maiores que as proteases (Pico I) e outro pico com proteínas menores (Pico III), que possivelmente foram retiradas pela diálise do Pico II em membranas com exclusão molecular de 12 kDa. Urtz e Rice (2000) utilizaram ultrafiltração em membrana de exclusão $10 \mathrm{kDa}$ anterior a uma única etapa de cromatografia por gel filtração de proteases de $B$. bassiana e obtiveram fator de purificação 48. Pré-tratamento de ELC de $B$. bassiana por fracionamento com 60 a $75 \%$ de saturação com sulfato de amônio (BIDOCHKA; KHACHATOURIANS, 1987) e com acetona a concentração final de 80\% (CHRZANOWSKA; BANAS; KOLACZKOWSKA, 2001) necessitaram de duas etapas cromatográficas para obter purificação de 17,8 e 49 vezes, respectivamente.

Tabela 1 Purificação de proteases extracelulares produzidas pelo fungo B.bassiana CG432 ativadas em broca-do-café.

\begin{tabular}{|c|c|c|c|c|c|c|}
\hline Fases & $\begin{array}{c}\text { Volume } \\
(\mathrm{mL})\end{array}$ & $\begin{array}{c}\text { Proteína } \\
\text { (mg) }\end{array}$ & $\begin{array}{c}\text { Atividade } \\
\text { proteases }\end{array}$ & $\begin{array}{c}\text { Rendimento } \\
(\%)\end{array}$ & $\begin{array}{l}\text { Atividade } \\
\text { específica }^{\mathrm{d}}\end{array}$ & $\begin{array}{c}\text { Fator de } \\
\text { purificação }\end{array}$ \\
\hline EP & 1400 & 163,5 & $15^{\mathrm{a}}$ & 100 & 0,09 & 1 \\
\hline $\begin{array}{c}\text { Ultrafiltração } \\
\left(\mathrm{C}_{3 \mathrm{k} \mathrm{D}}\right)\end{array}$ & 5 & 8,0 & $9,1^{\mathrm{a}}$ & 61 & 1,1 & 12 \\
\hline \multirow{3}{*}{$\begin{array}{l}\text { Sephadex } \\
\text { (Pico II) }\end{array}$} & 10 & 2,2 & $8,5^{\mathrm{a}}$ & 57 & 3,9 & 43 \\
\hline & 10 & 2,2 & $19^{\mathbf{b}}$ & - & 8,6 & - \\
\hline & 10 & 2,2 & $3,0^{\mathrm{c}}$ & - & 1,5 & - \\
\hline
\end{tabular}

${ }^{\mathrm{a}}$ substrato soro albumina bovina; ${ }^{\mathrm{b}}$ (Suc-Ala-Ala-Pro-Phe- $p$-nitroanilida) tripsina ${ }^{\mathrm{c}}(\mathrm{N}$-benzoil-Phe-Val-Arg- $p$-nitroanilida; ${ }^{\mathrm{d}}$ Atividade/mg de proteínas da fração

Fonte: Elaboração dos autores.

Figura 1. Cromatografia de gel filtração em Sephadex G-100 da fração $\mathrm{C}_{3 \mathrm{kDa}}$ concentrada por ultrafiltração contendo 8

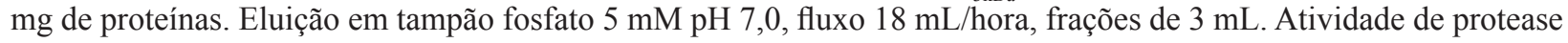
em tampão TRIS-Glicina pH 9,5 sobre soro albumina bovina. Pico II (frações 76-110). Volume morto $\left(\mathrm{V}_{0}\right)$ igual a $60 \mathrm{~mL}$ definido em solução de Blue-Dextran $5 \mathrm{mg} / \mathrm{mL}$ representado no gráfico (frações 0 a 20).

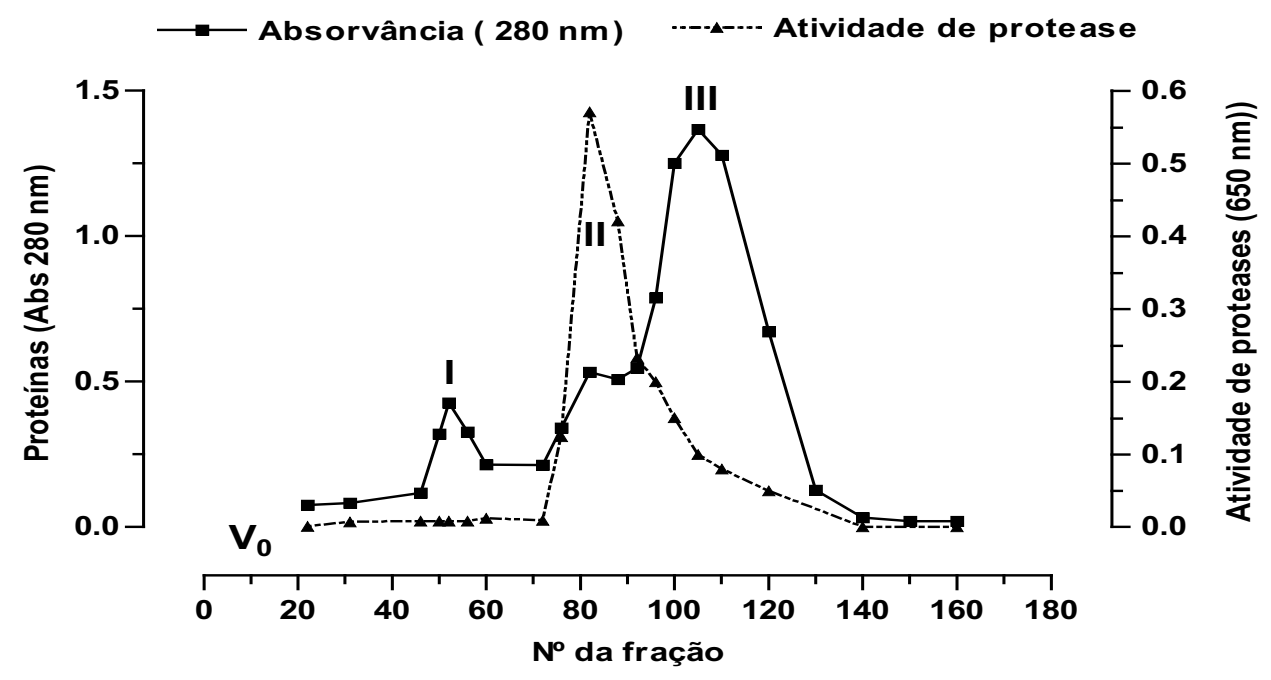

Fonte: Elaboração dos autores. 
As proteases do pico II apresentaram maior atividade proteolítica sobre o substrato específico de proteases tipo-subtilisina (Suc-Ala-Ala-ProPhe- $p$-nitroanilida) com $\mathrm{Km} 4 \times 10^{-4}$ que atividade específica sobre o substrato específico de proteases tipo-tripsina (N-Benzoil-Phe-Val-Arg$p$-nitroanilida). As proteases foram caracterizadas como serino-proteases contendo resíduos do aminoácido cisteína importantes para a atividade, pois foram inibidas por pré-incubação com PMSF e pCMB, respectivamente. Além disso, as proteases não foram caracterizadas como metalo e aspartato proteases, pois não foram inibidas por EDTA e AIA (Tabela 2).

Tabela 2. Atividade residual sobre substrato específico de proteases tipo subtilisina (Suc-Ala-Ala-Pro-Phe-pnitroanilida) das proteases do Pico II pré-incubadas com inibidores de proteases a $10 \mathrm{~mm}$.

\begin{tabular}{cc}
\hline Inibidor & Atividade de proteases residual (\%) \\
\hline Fluoreto Fenil-Metil-Sulfonil (PMSF) & 6,25 \\
$p$-cloromercuriobenzoato (pCMB) & 7,14 \\
Ácido Etileno Diamino Tetracético (EDTA) & 98,13 \\
Ácido Indol Acético (AIA) & 100 \\
\hline
\end{tabular}

Fonte: Elaboração dos autores.

A eletroforese PAGE em condições nativas demonstrou aparente homogeneidade do Pico II, pois revelou somente uma banda protéica por coloração com nitrato de prata (Figura 2A) e em zimograma com substrato gelatina revelada com Coomassie Brilhant Blue G-250 (Figura 2B). Tal homogeneidade foi confirmada pela revelação de uma única banda com ponto isoelétrico (pI) igual a 4,5 durante a isoeletrofocalização realizada na primeira dimensão da eletroforese PAGE-2D (Figura $3)$. Entretanto, e apesar dos resultados evidentes de purificação do pico II, a determinação da massa molecular, em condições dissociantes, realizada na segunda dimensão da eletroforese PAGE-2D revelou dois spots com massa moleculares de 23 e $26 \mathrm{kDa}$. O pI ácido, influenciado pela elevada porcentagem de resíduos de ácido aspártico (Tabela 3) é a principal característica estrutural que difere as proteases do Pico II de isoformas de proteinases tipo-subtilisina Pr1 com pI entre 9,3 e 10,2 produzidas por M. anisopliae, enquanto que a atividade tipo-subtilisina é a principal característica cinética que as difere das isoformas de proteases tipo-tripsina ácidas ( $\mathrm{Pr} 2)$ com pI entre 4,4 e 4,9 (St LEGER; BIDOCHKA; ROBERTS, 1994).

Figura 2. Eletroforese PAGE nativa a $10 \%$ de acrilamida da protease purificada de B. bassiana do Pico II. A). Revelação de proteínas por precipitação com nitrato de prata. B) Revelação da atividade sobre gelatina com Comassie Blue G-250. Resultados em duas repetições.

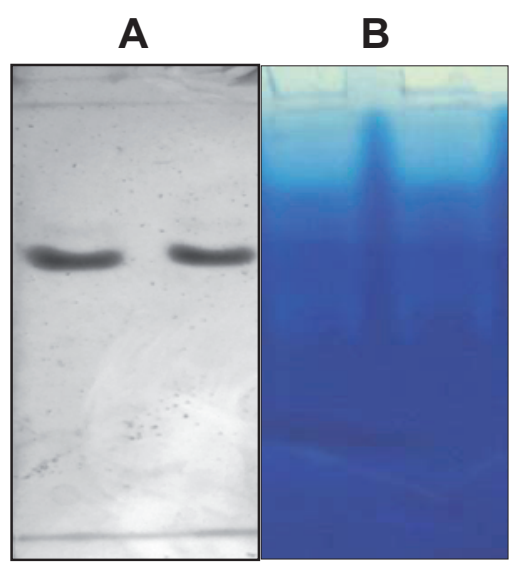

Fonte: Elaboração dos autores. 
Figura 3. Eletroforese PAGE em condições desnaturantes das proteases do pico II purificada de B. bassiana. Primeira dimensão: IPG de $13 \mathrm{~cm}$ (Bio-rad) pH 3-10. Segunda dimensão: SDS-PAGE com concentração de acrilamida de 12,5\%. Bandas reveladas por Comassie G-250. pH isoelétrico (pI) e Massa Molecular (MM) calculados pelo programa ImageMaster 2D Platinum

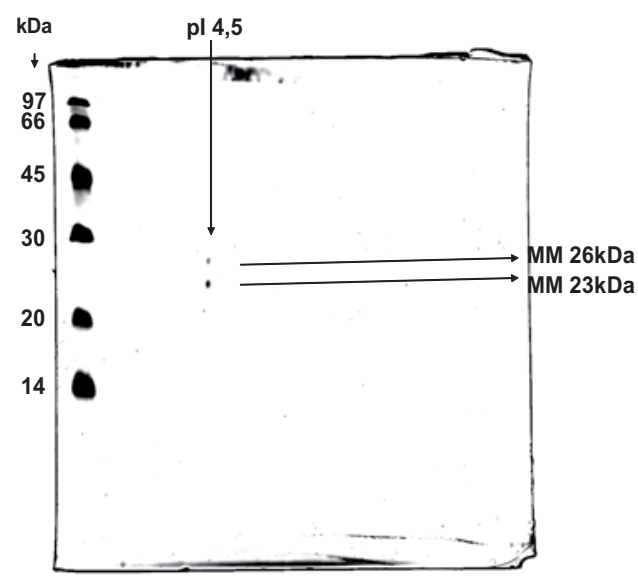

Fonte: Elaboração dos autores.

Espectros de massa

Os espectros de massa obtidos permitiram a determinação das relações massa/carga $(\mathrm{m} / \mathrm{z})$ dos peptídeos contidos nas amostras referentes aos spots de massa molecular $23 \mathrm{kDa}$ (Figura 4a) e 26 $\mathrm{kDa}$ (Figura 4b).

\section{Discussão e Conclusões}

A patogênese fúngica deve ser definida como um processo bioquímico, fisiológico e genético durante a infecção do inseto e formação da doença, uma vez que os fatores de virulência podem ser definidos como um processo envolvido na morte do inseto. As proteases extracelulares de B. bassiana têm sido caracterizados como um dos fatores de virulência apresentando um papel essencial para a sua patogenicidade. Devido a esses fatores foi investigada a extração, purificação e caracterização das proteases extracelulares de $B$. bassiana previamente reativadas em broca-do-café. Pois, as proteínas são os maiores constituintes da cutícula do inseto (HEPBURN, 1985) e possuem composições cuticulares e suscetibilidades diferentes para ação proteolítica. As proteases extracelulares produzidas por B. bassiana tem um papel importante na hidrólise da cutícula e penetração fúngica na hemocele. Uma vez na hemocele, o fungo prolifera por utilizar os nutrientes solúveis da hemolinfa (BIDOCHKA; KHACHATOURIANS, 1990). 
Figura 4. Espectro de peptide mass fingerprinting (PMF) gerado pelo spot de massa molecular $23 \mathrm{kDa}(\mathrm{A})$ e $26 \mathrm{kDa}$ (B) a partir do programa Flex Analysis 3.0.

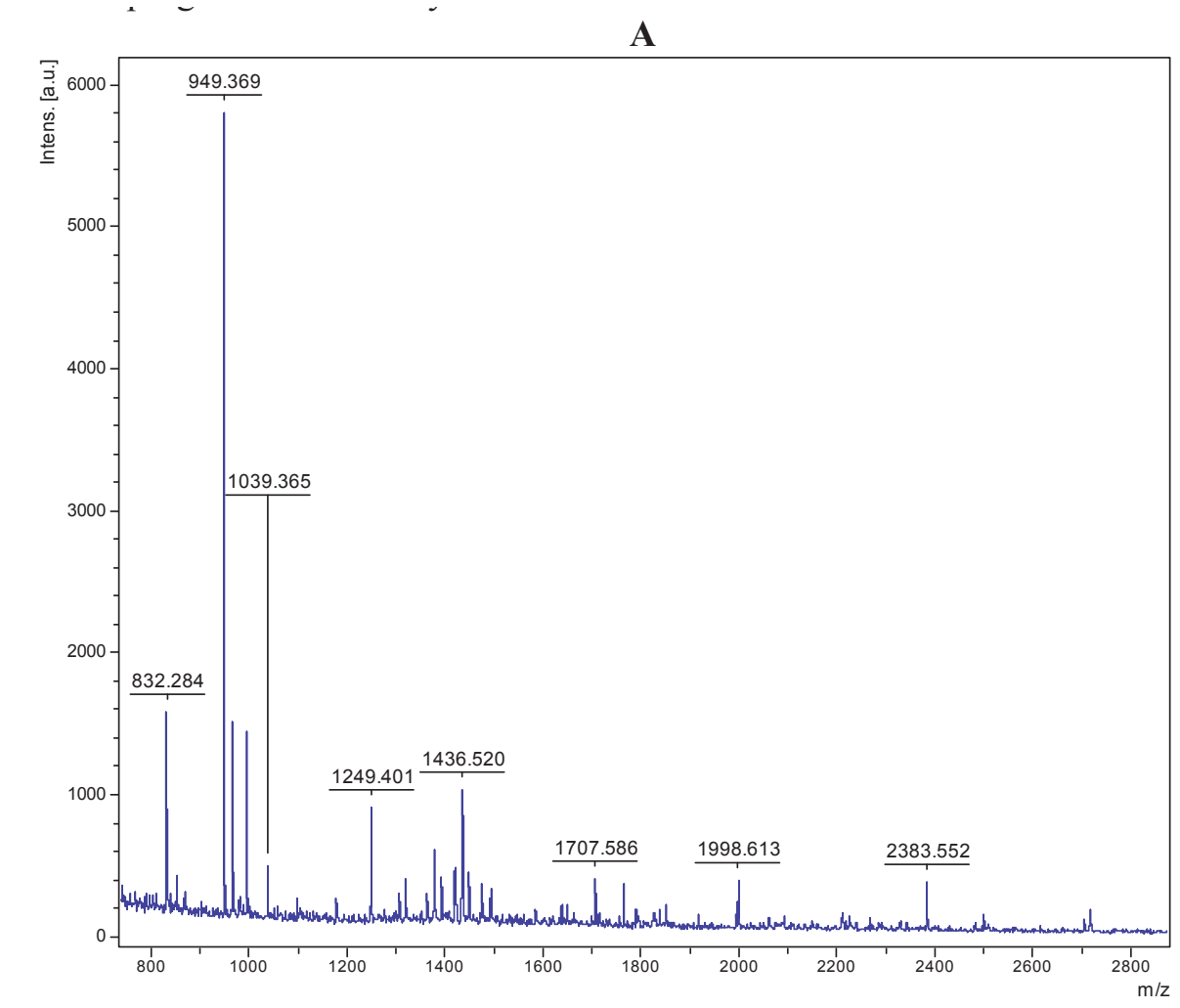

B

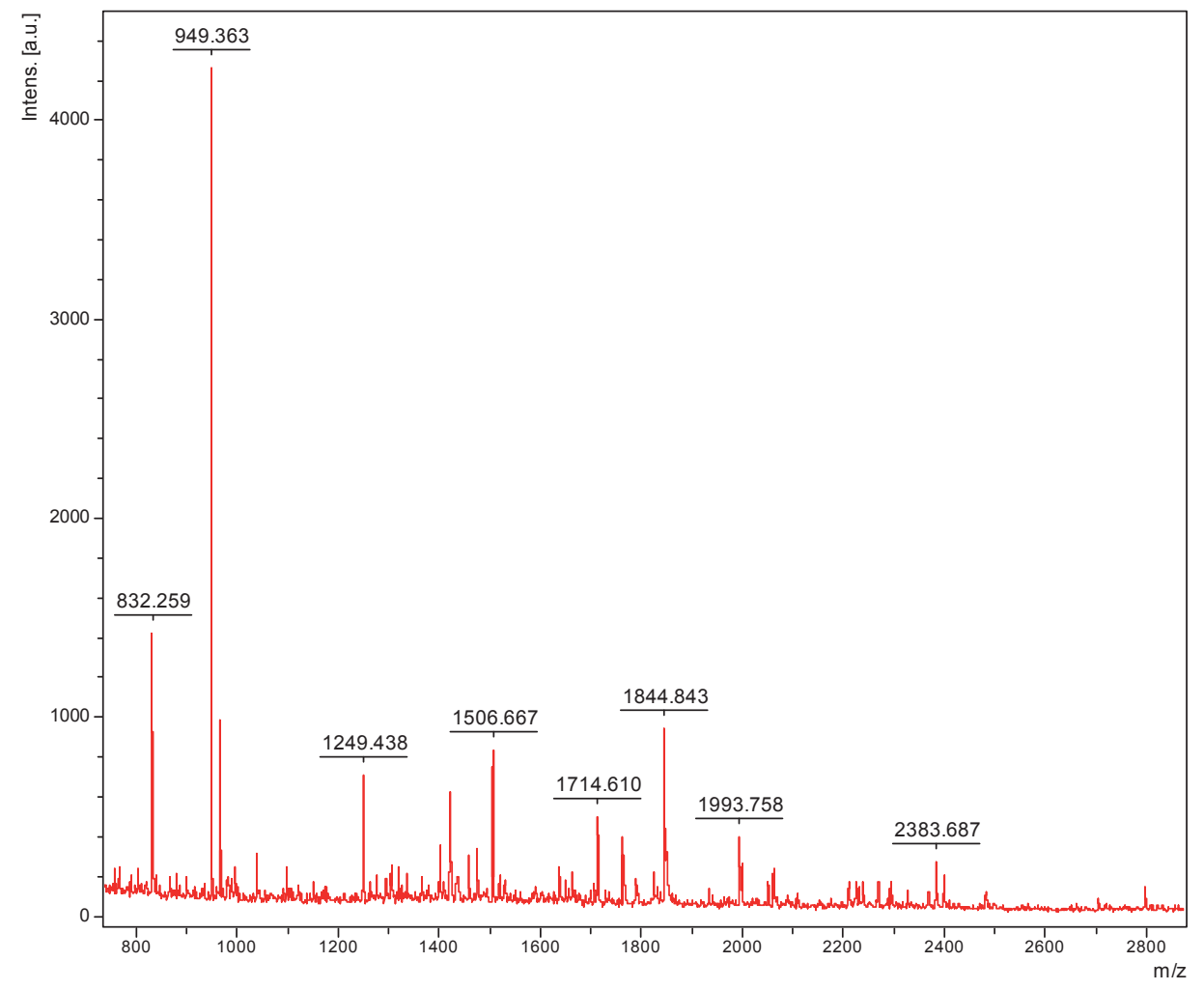

Fonte: Elaboração dos autores. 
As proteases caracterizadas neste trabalho apresentaram maior atividade sobre o substrato tipo-subtilisina e foram caracterizadas como serinoproteases e apresentaram pI igual a 4,5 com massas moleculares de 23 e $26 \mathrm{kDa}$ e atividade ótima em pH alcalino. St Leger et al. (1988) constatou que a quimoelastase ( $\operatorname{Pr} 1)$ produzida por Metarhizium anisopliae é utilizada como um fator de virulência por ocasionar a destruição localizada de proteínas cuticulares, que são capazes de invadir rapidamente o hospedeiro (Manduca sexta) com concomitante fornecimento de nutrientes e em 1989 demonstrou que Pr1 é a proteína produzida durante a infecção da cutícula do hospedeiro (St LEGER et al., 1989). Vários trabalhos sugerem que Pr1 de $M$. anisopliae realiza um papel essencial na penetração cuticular do inseto e subseqüente patogenicidade (St LEGER; CHARNLEY; COOPER, 1987a; St LEGER et al., 1988; St LEGER et al., 1989). Porém B. bassiana GK2016 produziu uma protease quando crescidas em meio contendo gelatina como única fonte de carbono e nitrogênio, após os procedimentos de purificação uma banda de proteína foi detectada por PAGE-SDS apresentando massa molecular estimada de $35 \mathrm{kDa}$, classificada como serino protease baseado na inibição por PMSF e apresentou atividade ótima em $\mathrm{pH}$ 8,5, apresentando características similares das proteases estudadas (BIDOCHKA; KHACHATOURIANS, 1987).

Bidochka e Khachatourians

demonstraram que a presença de grupos carboxílicos livres (resíduos alifáticos de aspartil e glutamil) das proteínas da cutícula formou sítios essenciais para a adsorção eletrostática de proteases básicas produzidas por fungos. Por outro lado, proteases ácidas (pI 4,0 a 5,3) de deteuromicetos entomopatogênicos com elevada atividade sobre substratos amídicos tipo-tripsina apresentaram preferência por resíduos hidrofóbicos da cutícula como sítio de ligação primário, incluindo a protease tipo-subtilisina de B. bassiana ( $\operatorname{Pr} 1 \mathrm{Bb}$ ) com pI 7,4, menor que outras subtilisinas, que apresentaram preferência por grupos hidrofóbicos dos resíduos de aminoácido Alanina das posições de p2 e p3 (sendo p1 o ponto de clivagem) de diferentes substratos amídicos específicos de proteases tipo-subtilisina (St LEGER; COOPER; CHARNLEY, 1987b). A adição de $0,5 \%$ de alanina inibiu a produção de proteases tipo-subtilisina em meio de cultura contendo cutícula de carrapato (CAMPOS et al., 2005). Estes resultados confirmam a participação das proteases na liberação da alanina como nutriente para crescimento fúngico, uma vez que a presença de aminoácido livre e disponível reduziu a necessidade da produção adicional de proteases. Estudos sobre a regulação do gene $\operatorname{Pr} 1$ de $M$. anisopliae confirmaram a hipótese de que o nível da mensagem é controlada por repressão catabólica, tanto para a produção de protease (St LEGER et al., 1992), como para regular o desenvolvimento do apressório (St LEGER et al., 1989), indicando que o nível dos nutrientes coordenam a regulação e a expressão dos produtos dos genes requeridos tanto para o desenvolvimento morfológico como para a degradação da proteína cuticular. Os artigos destacaram que a produção de proteases pode ainda ser influenciada por catabólitos produzidos por outras hidrolases importantes para a ação entomopatogênica.

A seqüência preditiva de aminoácidos a partir do seu DNA codificante (accession number U16305genebank Sequence Databank) revelou que a protease tipo-subtilisina de $B$. bassiana (Pr1Bb) é sintetizada como um zimogênio de 360 aminoácidos com massa molecular de $37.460 \mathrm{Da}$, cuja forma ativa apresenta 26.832 Da e resíduos de ácido aspártico, histidina e serina correspondentes ao sítio ativo em homologia a outras subtilisinas (JOSHI; St LEGER; BIDOCHKA, 1995). Sugerindo que a protease caracterizada no trabalho pode ter sido separada por ter sido ligado a uma proteína de regulação. Os autores citam o trabalho de Siezen et al. (1991) que demonstraram como pequenas diferenças na seqüência primária podem afetar substancialmente a eficiência proteolítica ao $\mathrm{pH}$ ótimo e a estabilidade térmica e oxidativa de proteases tipo-subtilisina. 
A estrutura do gene de outra serino-protease degradadora de cutícula produzida por $B$. bassiana (Bassiasin I) compreende 1137 pb (379 aminoácidos) e 3 íntrons com 69, 62 e 68 pb. A comparação da seqüência de aminoácidos deduzida do zimogênio apresentou elevada homologia com as serino-proteases tipo-subtilisina (Pr1) de M. anisopliae $(64,1 \%), \operatorname{Pr} 1 \mathrm{Bb}$ de $B$. bassiana (82,1\%) e proteinase $\mathrm{K}$ de Trítitrachium álbum (61\%), um fungo saprofítico (KIM et al., 1999). A literatura relata ainda a produção de uma protease extracelular tipo-subtilisina pelo basidiomiceto Pleurotus ostreatus (PoSI) com massa molecular de $75 \mathrm{kDa}$ mais elevadas que aquelas produzidas pelos deuteromicetos, provavelmente devido á natureza glicoproteica, porém muito semelhante ás proteases estudadas neste trabalho, pois apresenta atividade tipo-subtilisina em $\mathrm{pH}$ alcalino e pI 4,5 (PALMIERI et al., 2001). A consideração de outros autores quanto á influência da natureza dos substratos e catabólitos gerados pela ação concomitante das diferentes enzimas hidrolíticas para a patogênese dos fungos sobre os insetos, sustentam a hipótese que as características parcialmente distintas de proteases produzidas por outros deuteromicetos e até ascomicetos, podem ser resultantes da prévia ativação do fungo $B$. bassiana CG432 altamente virulenta sobre a broca-do-café, recém coletados a campo a partir de grãos de café infestados.

Os espectros de massa obtidos pela digestão das proteínas dos spots revelaram os valores de intensidade e de relação massa/carga dos fragmentos peptídicos detectados iguais a 23 e $26 \mathrm{kDa}$ pelo espectrômetro de massa. Estes dados foram confrontados com os dados de seqüências peptídicas armazenados em bancos de dados públicos (NCBI e Swiss-prot), porém esta tentativa de identificação por peptide mass fingerprinting (PMF) na plataforma on line do Mascot não permitiu chegar a uma análise conclusiva de identificação. A ausência de identificação pode refletir uma baixa qualidade dos espectros, devido à presença de picos contaminantes e impurezas nas amostras, ou pode estar associado a uma proteína que ainda não tenha sido descrita nos bancos de dados nos quais foram feitas às buscas por similaridade. Uma busca por seqüências peptídicas em banco de dados específicos ao fungo B. bassiana, ou mais similar taxonomicamente, pode fornecer dados mais consistentes quanto à identidade protéica referentes aos spots analisados. E futuramente compreender o funcionamento e a regulação da expressão dos genes Pr1 das proteases na broca-do-café, pois a proteômica analisa o produto final do genoma.

\section{Agradecimentos}

Os autores agradecem ao Prof. Dr. Pedro Manuel de Oliveira Janeiro Neves do Departamento de Agronomia da Universidade Estadual de Londrina pelo fornecimento da cepa de Beauveria bassiana; À Fundação Araucária, CNPq e Unidade Gestora do Paraná (SETI/Pr) pela concessão de bolsas e recursos financeiros para o desenvolvimento deste trabalho.

\section{Referências}

ALVES, S. B. Controle microbiano de insetos. 2. ed. Piracicaba: FEALQ, 1998. 1163 p.

BIDOCHKA, M. J.; KHACHATOURIANS, G. G. Basic proteases of entomopathogenic fungi differ in their adsorption properties to insect cuticle. Journal of Invertebrate Pathology, London, v. 64, n. 1, p. 26-32, 1994.

Protein hydrolysis in grasshopper cuticles by entomopathogenic fungal extracellular proteases. Journal of Invertebrate Pathology, London, v. 56, n. 3, p. 362-370, 1990.

. Purification and properties of an extracelular protease produced by the entomopathogenic fungus beauveria bassiana. Applied and Environmental Microbiology, Washington D.C, v. 53, n. 7, p. 1679-1684, 1987.

BRADFORD, M. M. A. Rapid and sensitive method for the quantitation of microgram quantities of protein utilizing the principle of protein-dye binding. Analytical Biochemistry, London, v. 72, n. 1-2, p. 248-254, 1976. 
CAMPOS, R. A.; ARRUDA, W.; BOLDO, J. T.; SILVA, M. V.; BARROS, N. M.; AZEVEDO, J. L.; SCHRANK, A.; VAINSTEIN, M. H. Boophilus microplus infection by Beauveria amorpha and Beauveria bassiana: SEM analysis and regulation of subtilisin-like proteases and chitinases. Current Microbiology, New York, v. 50, n. 5, p. 257-261, 2005.

CANDIANO, G.; BRUSCHI, M.; MUSANTE, L.; SANTUCCI, L.; GHIGGERI, G. M.; CARNEMOLLA, B.; ORECCHIA, P.; ZARDI, L.; RIGHETTI, P. G. Blue silver: a very sensitive colloidal Coomassie G-250 staining for proteome analysis. Electrophoresis, Weinhein, v. 25, n. 9, p. 1327-1333, 2004.

CHAPMAN, R. J. Integument. In: . The insects: structure and function. $4^{\text {th }}$ ed. Cambridge: Cambridge University Press, 1998, p. 415-440.

CHRZANOWSKA, J.; BANAS, J.; KOLACZKOWSKA, M. Purification and characterization of Beauveria bassiana proteinases. Acta Biotechnology, London, v. 21, n. 1, p. 73-81, 2001.

COLE, S. C. J.; CHARNLEY, A. K.; COOPER, R. M. Purification and partial characterization of a novel trypsin-like cysteine protease from Metarhizium anisopliae. FEMS Microbiology Letters, London, v. 113, n. 2, p. 189-196, 1993.

DAVIS, B. J. Disc electrophoresis. II; method and application to human serum proteins. Annals of the New York Academy of Sciences, New York, v. 121, n. 3, p. 404-427, 1964.

DUNN, M. J.; GÖRG, A. Two-dimensional polyacrilamide gel electrophoresis for proteome analysis. In: PENNINGTON, S. R.; DUNN, M. J. (Ed.). Proteomics from protein sequence to function. London: BIOS Scientific Publishers Limited, 2001. p. 225-245.

GIRALDO-CARDOZO, E. M.; LOPEZ-F, Y.; DELGADO, B. F.; VÉLEZ-A, P. E. Actividad lipolítica y proteolítica de Beauveria bassiana y Metarhizium anisopliae y su relación con la patogenicidade sobre Hypothenemus hampei (Coleoptera: Scolytidae). Revista Colombiana de Entomologia, Bogotá, v. 27, n. 2, p. 6165, 2001.

GUPTA, S. C.; LEATHERS, T. D.; EL-SAYED, G. N.; IGNOFFO, C. M. insect cuticle-degrading enzymes from the entomogenous fungus Beauveria bassiana. Experimental Mycology, Orlando, v. 16, n. 4, p. 132-137, 1992.

HARTREE, E. F. Determination of protein: A modification of the Lowry method that gives a linear photometric response. Analytical Biochemistry, London, v. 48 , n. 2, p. 422-427, 1972.
HEPBURN, H. R. Structure of the Integument. In: KERKUT, G. A.; LGILBER, I. T. (Ed.). Comprehensive insect physiology, biochemistry and pharmacology. Whashington: Pergamon Oxford, 1985. v. 3, p. 1-58.

ITO, E. T.; VARÉA-PEREIRA, G.; MIYAGUI, D. T.; PINOTTI, M. H. P.; NEVES, P. M. O. J. Production of extracellular proteases by a Brazilian strain of Beauveria bassiana reactivated on coffee berry borer, Hipothenemus hampei. Brazilian Journal of Biology and Biotechnology, Curitiba, v. 50, n. 2, p. 217-223, 2007.

JOSHI, L.; StLEGER, R. J.; BIDOCHKA, M. J.Cloning of a cuticle-degrading protease from the entomopathogenic fungus, Beauveria bassiana. Microbiology Letters, London, v. 125, n. 1, p. 211-218, 1995.

KIM, H. K.; HOE, H. S.; SUH, D. S.; KANG, S. C.; HWANG, C.; KWON, S. T. Gene structure and expression of the gene from Beauveria bassiana encoding bassiasin I, an insect cuticle-degrading serine protease. Biotechnology Letters, New York, v. 21, n. 12, p. 777-783, 1999.

KUCERA, M.; SAMSINAKOVA, A. Toxins of the entomophagous fungus Beauveria bassiana. Journal of Invertebrate, London, v. 12, n. 3, p. 316-320, 1968.

LAEMMLI, U. K. Cleveage of structural proteins during the assembly of the head of bacteriphage T4. Nature, London, v. 227, n. 5259, p. 680-685, 1970.

NEVES, P. M. O.; HIROSE, E. Seleção de isolados de Beauveria bassiana para o controle biológico da brocado-café, Hypothenemus hampei (Ferrari) (Coleóptera: Scolytidae). Neotropical Entomology, Londrina, v. 34, n. 1, p. 77-82, 2005.

NEVILLE, A. C. Biology of the arthropod cuticle. In: GÜNTER, K. K. Zoophysiology and ecology. Berlim: Springer-Verlag K.G, 1975. p. 71-123. (Chapter, 4).

NIELSEN, B. L.; BROWN, L. R. The basis for colored silver-protein complex formation in stained polyacrylamide gels. Analitical Biochemistry, London, v. 141, n. 2, p. 311-315, sept. 1984.

PALMIERI, G.; BIANCO, C.; CENNAMO, G.; GIARDINA, P.; MARINO, G.; MONTI, M.; SANNIA, G. Purification, characterization, and functional role of a novel extracellular protease from Pleurotus ostreatus. Applied and Environmental Microbiology, Washington D.C, v. 67, n. 6, p. 2754-2759, 2001.

SIEZEN, R. J.; VOS, W. M.; LEUNISSEN, J. A. M.; DJIKSTRA, W. D. Homology modeling and protein engineering strategy of subtilases, the family of subtilisin-like serine proteinases. Protein Engineering, Switzerland, v. 4, n. 4, p. 719-737, 1991. 
St LEGER, R. J.; CHARNLEY, A. K.; COOPER, R. M. Cuticle-degrading enzymes of entomopathogenic fungi: synthesis in culture on cuticle. Journal Invertebrate Pathology, London, v. 48, n. 1, p. 85-95, 1986a.

Cuticle-degrading enzymes of entomopathogenic fungi: cuticle degradation in vitro by enzymes from entomopathogens. Journal Invertebrate Pathology, London, v. 47, n. 2, p. 167-177, 1986b.

St LEGER, R. J.; BIDOCHKA, M. J.; ROBERTS, D. $\mathrm{W}$. Isoforms of the cuticle-degrading prl proteinase and production of a metalloproteinase by Metarhizium anisopliae. Archives of Biochemistry and Biophysics, London, v. 313, n. 1, p. 1-7, 1994.

St LEGER, R. J.; BUTT, T. Q.; STAPLES, R. C.; ROBERTS, D. W. Synthesis of proteins including a cuticle-degrading protease during differentiation of the entomopathogenic fungus Metarhizium anisopliae. Experimental Mycology, London, v. 13, n. 3, p. 253-262, 1989.

St LEGER, R. J.; CHARNLEY, A. K.; COOPER, R. M. Characterization of cuticle-degrading proteases produced by the entomopathogen Metarhizium anisopliae. Archives Biochemistry Biophysites, New York, v. 253, n. 1, p. 221232, 1987a.

St LEGER, R. J.; COOPER, R. M.; CHARNLEY, A. K. Distribution of chymoelastase and trypsin-like enzymes in five species of entomopathogenic deuteromycetes. Archives Biochemistry Biophysics, London, v. 258, n. 2, p. 123-131, 1987b.
St LEGER, R. J.; DURRANDS, P. K.; CHARNLEY, A. K.; COOPER, R. M. Role of extracellular chymoelastase in the virulence of Metarhizium anisopliae for Manduca sexta. Journal Invertebrate Pathology, London, v. 52, n. 2, p. 285-293, 1988.

St LEGER, R. J.; FRANK, D. C.; ROBERTS, D. W.; STAPLES, R. C. Molecular cloning and regulatory analysis of the cuticle-degrading-protease structural gene from the entomopathogenic fungus Metarhizium anisopliae. European Journalof Biochemistry, London, v. 204, n. 2, p. 991-1001, 1992.

TIAGO, P. V.; FUNGARO, M. H. P.; FARIA, M. F.; FURLANETO, M. C. Effects of double-stranded RNA in Metarhizium anisopliae var. acridum and Paecilomyces fumoroseus on protease activities, conidia production and virulence. Canadian Journal of Microbiology, Ottawa, v. 50, n. 5, p. 335-339, 2004

URTZ, B. E.; RICE, W. C. Purification and characterization of a novel extracellular protease from Beauveria bassiana. Mycological Research, London, v. 104, n. 2, p. 180-186, 2000.

YANG, J. Z.; BASTIAN, K. C.; MOORE, R. D.; STOBAUGH, J. F.; BORCHARDT, R. T. Quantitative analysis of a model opioid peptide and its cyclic prodrugs in rat plasm using high-performance liquid chromatography with fluorescence and tandem mass spectrometric detection. Journal of Chromatography B., London, v. 780, n. 2, p. 269-281, 2002. 